\title{
Commentary
}

\section{Beyond the Darkness: Research on Participation in Online Media and Discourse}

\author{
Claes de Vreese \\ Amsterdam School of Communication Research, University of Amsterdam, The Netherlands; E-Mail: c.h.devreese@uva.nl
}

Submitted: 2 November 2020 | Accepted: 11 November 2020 | Published: 3 February 2021

\begin{abstract}
This commentary reflects on the notion of 'dark participation' which is central in this thematic issue. It asks whether there are patches of light and whether our research is becoming too obsessed with the darkness?
\end{abstract}

\section{Keywords}

democratic backsliding; misinformation; participation; polarization; trust

\section{Issue}

This commentary is part of the issue "Dark Participation in Online Communication: The World of the Wicked Web" edited by Thorsten Quandt (University of Münster, Germany).

(C) 2021 by the author; licensee Cogitatio (Lisbon, Portugal). This article is licensed under a Creative Commons Attribution 4.0 International License (CC BY).

In an era of polarization, democratic backsliding, and decreasing media freedom, it is important for the scholarly community to occasionally take a step back. It is upon our community to provide clear analyses of these developments and to provide systematic empirical evidence about the nature, scope, and conditionalities of them. The current thematic issue of Media and Communication is welcome because it does just that.

The topics are not trivial: a) Spread of mis- and disinformation; b) polarization of and by political elites, in the media, in media use; c) increasing distrust of journalism and news avoidance; and d) changing (read 'worsening') civil discourse, especially online. Welcome to the research agenda of a communication scholar! Given the potential far reaching consequences for democratic processes and our societies at large, evidence that reaches beyond single cases or single countries is most welcome.

This thematic issue offers insights from Germany, Taiwan, the European Union, Russia, and the United States. Some research looks at the content of political discourse, in 'fake news,' in comments sections, and in visuals. The studies include social media platforms like Twitter and YouTube. Other research focuses on the user, and how personality, motivation, and gratifications affect both information usage and processing. The studies span from interviews to content analyses and survey data. In this respect the thematic issue delivers on important dimensions: Evidence from different countries, content, and user perspectives; and multiple methods being deployed.

The thematic issue takes its departing point in the concept of 'dark participation.' This concept has received the most comprehensive treatment by Quandt (2018). It is a broad concept, trying to capture "negative, selfish, or even deeply sinister contributions" (Quandt, 2018, p. 40). Quandt offers a generic introduction to the concept, distinguishing how dark participation can come from different actors, with different reasons, focusing on different objects, reaching different audiences, through different processes. This is a useful overview, but also one that leaves the concept fully open for further delineation.

The dark participation concepts can leave a scholar or citizen in a depressed mood. As Westlund and Ekström (2018) point out we came from a period where there was a focus on 'positive forms of participatory journalism.' In their view, this research did not signal or problematize dark participation. Quandt (2018) paints the dark picture. He makes intentional reference to Hobbes but an attentive reader will also have found this important sentence: "If you now believe that the future is all doom and gloom, then you have stepped into a trap that I intentionally set" 
(p. 44). This (for scholarly articles) somewhat unconventional tool is important, beyond the stylistic effect.

In recent years there has been a turn in the societal discussions and in the research agenda, and the 'doom and gloom' perspective now seems pervasive. This not only holds true for the perspective of citizen participation in (online) (news) media, but also for the broader field of political journalism and communication. Van Aelst et al. (2017), including myself, indeed focus on six concerns when describing the changes in contemporary media ecologies: 1) Declining supply of political information; 2) declining quality of news; 3 ) increasing media concentration and declining diversity; 4 ) increasing fragmentation and polarization; 5) increasing relativism; and 6 ) increasing inequality in political knowledge. Across these concerns, a core challenge is 'epistemic relativism,' where all information is treated equal, whether provided by journalists or citizens, whether positive or negative, whether distributed through traditional or online, automated, digital channels. In the review of these concerns it is pointed out that far from all empirical evidence supports an unequivocal legitimacy of the concerns.

This raises a bigger question: In the midst of worries about, and research into trolling, incivility, conspiracy, mis- and disinformation, automated pollution of the information environment, populism, and democratic backsliding, is there also space for optimism and a positive research agenda? Whether that is work driven by an 'always look on the bright side of life' or 'post tenebras lux,' light after darkness philosophy, can remain open. But it seems important to balance our fascination with 'darkness' with questions about positive engagements with media.

Whether it be instances of increased media trust, the possible upsides for journalism during the Covid-19 pandemic, examples of constructive news, the still positive correlates between political interest and news media usage, or the focus on engagement in media and politics which is also evidenced in recent elections. I am not advocating a return to past decades. It is an invitation for us to think about the conditions and mechanisms for positive contributions to a healthy public debate. And to think about how we can make research contributions constructive and actionable. There are tangible examples like the Center for Media Engagement (https://mediaengagement.org) or the Media for Democracy (https://mediafordemocracy.org) initiative around the 2020 United States' elections, offering advice for both media and citizens. The bottom line is, that in the era of darkness, it will also be a task of scholars to provide guidance on the upsides.

\section{Conflict of Interests}

The author declares no conflict of interests.

\section{References}

Quandt, T. (2018). Dark participation. Media and Communication, 6(4), 36-48.

Van Aelst, P., Strömbäck, J., Aalberg, T., Esser, F., de Vreese, C. H., Matthes, J., . . . Stanyer, J. (2017). Political communication in a high-choice media environment: A challenge for democracy? Annals of the International Communication Association, 41(1), 3-27.

Westlund, O., \& Ekström, M. (2018). News and participation through and beyond proprietary platforms in an age of social media. Media and Communication, 6(4), $1-10$.

\section{About the Author}

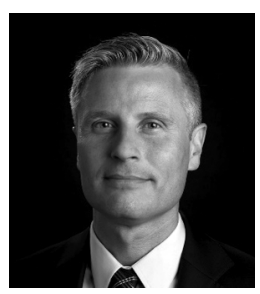

Claes de Vreese is Faculty Professor of Al \& Democracy and Professor of Political Communication, ASCoR, University of Amsterdam. He is President (2020-2021) of the International Communication Association, ICA. Twitter: @claesdevreese. 